\title{
Synthesis and Examination of Polymers to Improve Pattern Clarity and Resistance Properties of Phthalocyanine Color Pixels in Liquid Crystal Display
}

\author{
Chun Yoon, ${ }^{*}$ Jae-hong Choi, ${ }^{\dagger}$ and Jae Pil Kim ${ }^{\ddagger}$
}

Department of Chemistry, Sejong University, Seoul 143-747, Korea. *E-mail: chuny@sejong.ac.kr

${ }^{\dagger}$ Department of Textile System Engineering, Kyungpook National University, Daegu 702-701, Korea

¿Department of Materials Science and Engineering, Seoul National University, Seoul 151-742, Korea Received September 16, 2010, Accepted December 22, 2010

Key Words : Polymeric binders, Color filter photo resist, Color pixels, Pigments, Liquid crystal display

Pigments, polymeric binders and multifunctional monomers are components of a color filter photo resist (CFPR) that is a key material in the manufacturing of color filters of LCD..$^{1-5}$ This study focused on polymeric binders that affect pattern clarity and their resistance properties, ${ }^{6-8}$ The study was responding to several purposes for LCD that required the introduction of new binders. First, the traditional binder, widely used for a long time, was prepared from benzyl methacrylate and methacrylic acid, ${ }^{9}$ which is not suitable for the recent trend of blue pigment. The recent blue pigment (CI Pigment Blue 15:6) is a derivative of phthalocyanine, with smaller particle size to obtain a high contrast ratio. The
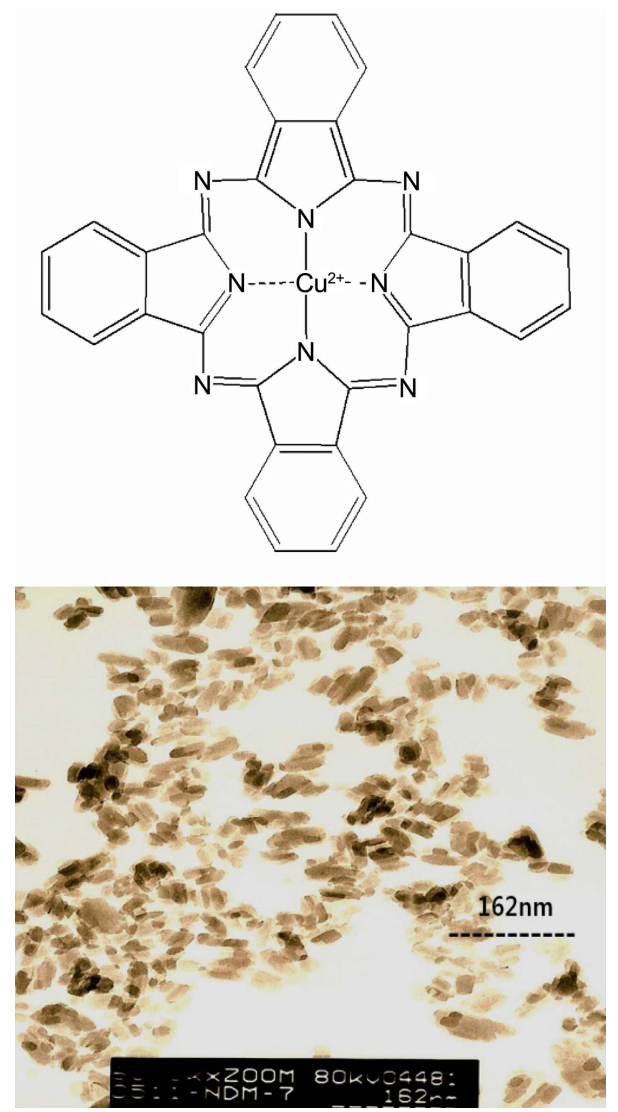

Figure 1. An electron microscope image (TEM) of phthalocyanine blue pigment (CI Pigment Blue 15:6) with very fine particle shape and its chemical structure. pigments for a high contrast ratio usually have a particle size in the range of 40-60 nm, while conventional pigments have a particle size of around $90 \mathrm{~nm}$. Figure 1 shows the chemical structure and an electron microscope image (TEM) of recent phthalocyanine blue pigment with very fine particle shape.

The smaller sized pigment usually has a larger surface area, which should increase interactions among particles resulting in poor properties such as agglomeration, poor pattern clarity and resistance. ${ }^{10}$ To minimize the above drawbacks, which increase the influences of binders on pigment particles, monomers such as 2-hydroxyethyl methacrylate and hydroxybutyl methacrylate were introduced to produce a hydrogen bond between the binder and the pigment, as shown in Figure 2.

Second, introductions of less expensive materials, such as styrene instead of benzyl methacrylate, have been employed to contribute to the extreme competiveness of the LCD industry. For this reason, there has been research conducted on binders containing new components. In this study, polymeric binders were synthesized from styrene, benzyl methacrylate, 2-hydroxy methacrylate, hydroxybutyl methacrylate and methacrylic acid. The chemical structures are presented in Figure 3. A commercial binder (SMA 1000) and the traditional binder (BI-1) that was prepared from benzyl methacrylate and methacrylic acid were also studied as comparisons with the new binders. The SMA 1000 was selected because it contained styrene and a large quantity of anhydride (precursor of carboxylic acid); in addition, it had good availability in terms of commercialization. Finally, to evaluate the properties, CFPRs were prepared from these

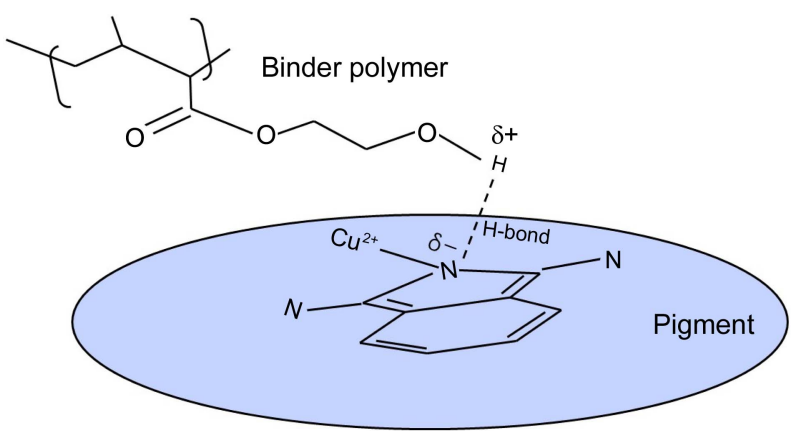

Figure 2. Influence of binder on pigment with hydrogen bond. 


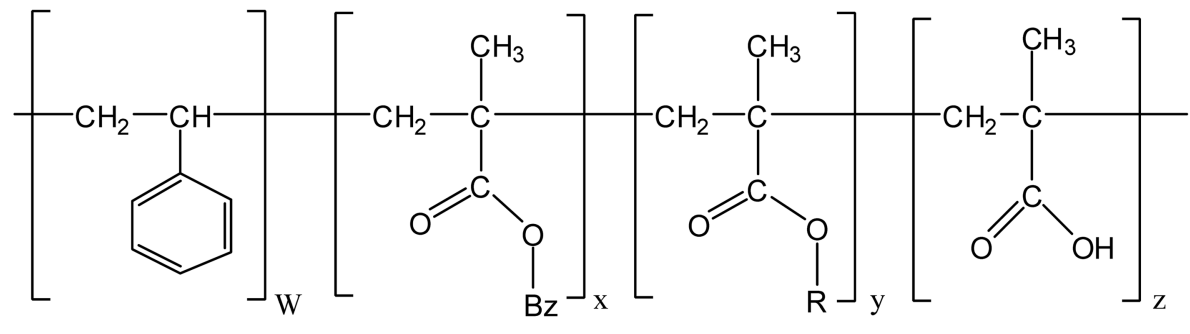

$\mathrm{R}=\mathrm{CH}_{2} \mathrm{CH}_{2} \mathrm{OH}, \mathrm{C}_{4} \mathrm{H}_{8} \mathrm{OH}$

Figure 3. Structure of synthesized polymeric binders to improve pixel pattern properties.

Table 1. Characteristics of the synthesized polymeric binders and a commercial binder

\begin{tabular}{cccrrr}
\hline \multirow{2}{*}{ Binder } & Component & Monomer & \multicolumn{3}{c}{ Average molecular weight (g/mol) } \\
\cline { 3 - 6 } & & molar ratio & \multicolumn{1}{c}{ Mn } & Mw & PDI \\
\hline BI-1 & Benzyl methacrylate/methacrylic acid & $7 / 3$ & 8,608 & 14,765 & 1.71 \\
BI-2 & Styrene/2-hydroxyethyl methacrylate/methacrylic acid & $5 / 2 / 3$ & 18,533 & 27,363 & 1.47 \\
BI-3 & Styrene/hydroxybutyl methacrylate/methacrylic acid & $5 / 2 / 3$ & 24,143 & 38,319 & 1.58 \\
SMA 1000 & Styrene/maleic anhydride & $1 / 1$ & 2,000 & 5,500 & 2.75 \\
\hline
\end{tabular}

binders.

The polymeric binders were synthesized by the usual method, using a propylene glycol monomethyl ether acetate (PGMEA) solvent and an AIBN (2,2'-Azobisisobutyronitrile) initiator under nitrogen purging with approximately 30 $\%$ concentration.

The average molecular weights of the polymeric binders, measured using GPC and molar ratios, are listed in Table 1. The molecular weights of the binders are in the range of $5,500-38,300 \mathrm{~g} / \mathrm{mol}$. The prepared polymer solutions were used without isolation for CFPR preparation, and concentrations of each polymer in the prepared solutions showed a range of about $26-28 \%$. To evaluate the performances of the binders, CFPRs were prepared in the traditional manner, formulating dispersed blue phthalocyanine pigments, binders, multifunctional monomers, photo initiators, surfactants and solvents. ${ }^{9}$ In these preparations, the binders were employed as solutions with a quantity of $3 \%$ weight. The prepared CFPRs were negative types, in which the exposed part was cured and not washable by alkali-developer because of the cross-linking of multifunctional monomers, while the unexposed part was washable by alkali-developer because of the carboxylic acid in the binders. Coating of the CFPRs onto glass was carried out using a spin coater to a thickness of about 1-2 $\mu \mathrm{m}$. The amount of UV exposure with a patterned photo mask was usually $200 \mathrm{~mJ} / \mathrm{cm}^{2}$ at $360 \mathrm{~nm}$, but varied depending on the type and quantity of the photo initiators.

In this paper, two properties of the development process were researched. First, the relationship between the binder and the development property was investigated. The optimal properties for the development process should not give rise to remainder or exfoliation. Micrographs were taken to evaluate the performances of the synthesized binder and are shown in Figure 4 . The size of the entire pattern was $2 \times 2$

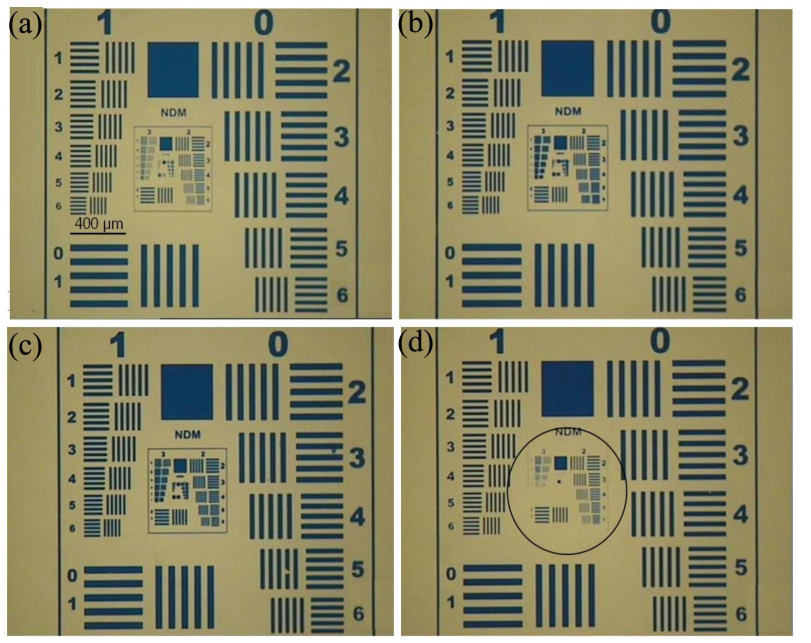

Figure 4. Micrographs of patterns generated on glass after the development process: (a) BI-1 (b) BI-2 (c) BI-3 (d) SMA 1000.

$\mathrm{mm}$, and the inner rectangular bars were typically $40 \times 400$ $\mu \mathrm{m}$.

As shown in Figure 4, CFPRs prepared from BI-1, BI-2, BI-3 gave good development properties that produced no exfoliation and no remainder as expected; however the CFPRs containing the commercial binder (SMA 1000) showed some exfoliation of the inner small rectangular. This exfoliation might be the result of low molecular weight and the large quantity of acid; therefore small patterns can be easily exfoliated by increasing the washablity, as shown in micrograph (d).

Second, the relationship between binder and the pattern clarity was investigated.

As shown in Figure 5, the CFPRs prepared from BI-2, BI3 and SMA 1000 gave rise to good properties of pattern clarity except in the CFPR prepared from BI-1, which 

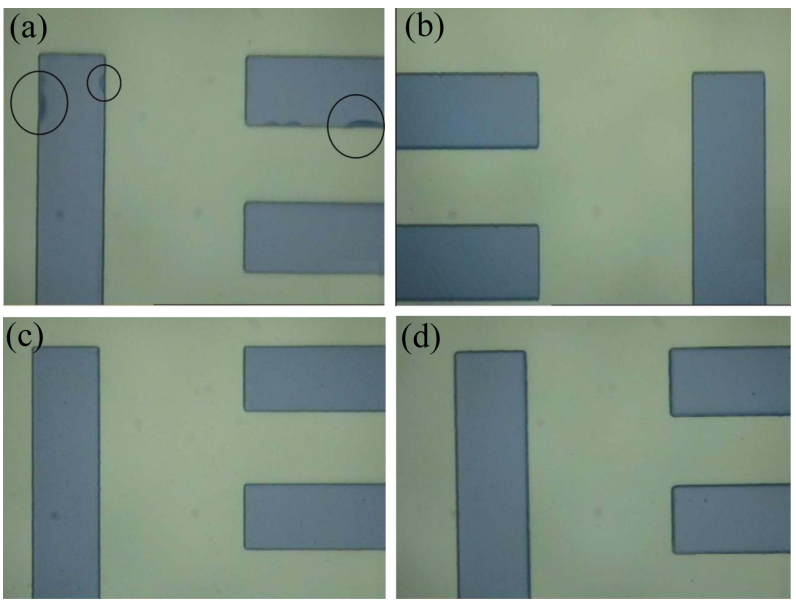

Figure 5. Micrographs of patterns generated on glass after the development process: (a) BI-1 (b) BI-2 (c) BI-3 (d) SMA 1000.

presented some agglomeration of pigment on the edge of the pattern. As discussed, fine pigment particles can be easily agglomerated due to their large surface area. Another interesting result is found in Figure 5. The molar ratio of the binder BI-1 for the polar component (methacrylic acid) and non-polar component (benzyl methacrylate) is 30:70, while the molar ratio of other binders is 50:50. Thus, this study can conclude that more polar binder is suitable for improving dispersion stability of the polar phthalocyanine pigment with fine particle shape based on increased interaction with each other.

The binding force of binders can also affect color properties, as this force plays an important role in preventing color changes $(\Delta \mathrm{E})$ of pigments via sublimation or decomposition. If sublimation or decomposition takes place, color change will occur. However, good binders minimize this color change, which is evaluated by a $\Delta \mathrm{E}$ value of CIE $\mathrm{xy}$ color coordination. This property is heat resistant and was tested by treating the test materials at $250{ }^{\circ} \mathrm{C}$ for 1 hour. In addition, chemical resistance to isopropyl alcohol (IPA) and N-methylpyrrolidone (NMP) was tested by dipping the test materials in the above chemicals at $25{ }^{\circ} \mathrm{C}$ for 30 minutes. Color differences were recorded in the same manner as heat resistance results; the results of the heat and chemical resistance tests are represented in Table 2.

As shown in Table 2, the binders BI-2 and BI-3 gave better $\Delta \mathrm{E}$ values of 2.5 and 2.6 in heat resistance compared to binder BI-1 ( $\Delta \mathrm{E} 3.1)$ or SMA $1000(\Delta \mathrm{E} 2.9)$. At high

Table 2. Resistance to heat and chemicals of the prepared binders

\begin{tabular}{|c|c|c|c|}
\hline \multirow[t]{2}{*}{ CFPR } & \multirow{2}{*}{$\begin{array}{l}\text { Heat resistance } \\
\left(\Delta \mathrm{E}, 250^{\circ} \mathrm{C} / 1 \mathrm{hr}\right)\end{array}$} & \multicolumn{2}{|c|}{$\begin{array}{l}\text { Chemical resistance } \\
\left(\Delta \mathrm{E}, 25^{\circ} \mathrm{C} / 30 \mathrm{~min}\right)\end{array}$} \\
\hline & & NMP & IPA \\
\hline BI-1 & 3.1 & 3.6 & 2.5 \\
\hline BI-2 & 2.6 & 2.7 & 2.1 \\
\hline BI-3 & 2.5 & 2.7 & 2.0 \\
\hline SMA 1000 & 2.9 & 3.1 & 2.0 \\
\hline
\end{tabular}

temperature $\left(250^{\circ} \mathrm{C}\right)$, pigments generally tend to sublime, agglomerate and decompose with resulting color changes. In addition, binding force plays an important role in preventing color change in chemical resistance; the binders BI-2 and BI-3 each gave $\Delta \mathrm{E}$ value of 2.7 on the NMP test, and gave $\Delta \mathrm{E}$ values 2.1 and 2.0 , respectively on the IPA test. Other binders gave somewhat poorer results in the NMP and IPA tests, as listed in Table 2. Finally, the study concluded that the polymeric binders containing monomers such as styrene, 2-hydroxyethyl methacrylate and hydroxybutyl methacrylate improved development and resistance properties as expected and suggested good suitability of polar phthalocyanine pigment for high contrast ratio with fine particle shape. The introduction of 2-hydroxyethy methacrylate or hydroxybutyl methacrylate augmented the binding force without an increased quantity of carboxylic acid to affect the exfoliation of patterns.

\section{Experimental Section}

Equipment and Materials. Color difference data $(\Delta \mathrm{E})$ and CIE xy values were measured using an MCPD 3700 spectrophotometer specially designed for LCD color filters (Otsuka Electronics, Japan). A spin-coater (Sungwon Electronics, Korea) was used to coat CFPR onto glass substrates. The particle sizes of the pigments were recorded on a particle size analyzer (Par III, Otsuka Electronics, Japan). The thickness of materials coated onto the glass was measured using a profiler (Alpha-Step IQ, KLA Tencor, USA). A photomask aligner (MDE-400, Midas System Co., Ltd., Korea) was used for UV-curing of CFPR. GPC (ACME 9000, Young Lin instrument Co., Ltd., Korea) was used for measuring average molecular weight. The pigment selected was specially designed for LCD color filters. The pigment used in this study was CI Pigment Blue 15:6 (Fastogen EP193, DIC Corp., Japan). Glass ( $370 \mathrm{~mm} \times 470 \mathrm{~mm} \times 0.63 \mathrm{~T}$, $5 \mathrm{~K}$ Super) used as a coating substrate in this study was manufactured by Samsung Corning Precision Glass, Ltd. (Korea). The glass was cut into suitable fragments $(5 \times 5$ $\mathrm{cm}$ ) for the coating tests. The dispersant Disperbyk 163 used for grinding the pigments was manufactured by BYKChemie (Germany). Chemicals for CFPRs: dipentaerythritol penta-/hexa-acrylate as a multifunctional monomer was supplied by Aldrich Chemicals (USA); Irgacure-369 as a photo initiator was supplied by Ciba Specialty Chemicals; and FC4432 as a surfactant was supplied by 3 M Company (USA). The chemicals for binders, namely styrene, 2-hydroxyethyl methacrylate and methacrylic acid, were supplied by Junsei chemicals (Japan), and benzyl methacrylate and hydroxybutyl methacrylate were supplied by Aldrich chemicals (USA).

Preparation of CI Pigment Blue 15:6 Paste. 15 g Blue pigment was stirred into $15 \mathrm{~g}$ dispersant (Disperbyk 163, active ingredient 45\%), $1 \mathrm{~g}$ Solsperse 5000 (Lubrizol Ltd.) and $70 \mathrm{~g}$ PGMEA (propylene glycol methyl ether acetate, Aldrich Chemicals, USA) for about 1 hour in the wetting process. The mixture was ground with $300 \mathrm{~g}$ zirconia beads 
(diameter: $0.5 \mathrm{~mm}$ ) in a plastic vessel (diameter: $7.5 \mathrm{~cm}$; height: $15 \mathrm{~m}$ ) for 5 hours. A gear-shaped agitator (diameter: $5 \mathrm{~cm}$ ) was employed at a rotation speed of about 3,000 rpm. The pigment paste was cooled to $15-20{ }^{\circ} \mathrm{C}$ using an icewater bath during grinding. The beads were filtered off using a sieve to collect the pigment paste.

Poly(benzyl methacrylate-co-methacrylic acid) Binder Solution (BI-1): Benzyl methacrylate $(24.80 \mathrm{~g}, 0.140 \mathrm{~mol})$ and methacrylic acid $(5.20 \mathrm{~g}, 0.060 \mathrm{~mol})$ were stirred into $69.1 \mathrm{~g}$ PGMEA under nitrogen purging to expel oxygen. The polymerization was carried out at $80^{\circ} \mathrm{C}$ for 10 hours using $0.9 \mathrm{~g}$ of 2,2'-Azobisisobutyronitrile (Junsei Chemicals, Japan) as a radical initiator. Polymer content was about $27.1 \%$.

Poly(styrene-co-2-hydroxyethyl methacrylate-co-methacrylic acid) Binder Solution (BI-2): Methacrylic acid (7.45 g, $0.086 \mathrm{~mol})$, styrene $(15.02 \mathrm{~g}, 0.144 \mathrm{~mol})$ and 2hydroxyethyl methacrylate $(7.51 \mathrm{~g}, 0.058 \mathrm{~mol})$ were stirred into $69.1 \mathrm{~g}$ PGMEA. Polymerization and preparation of the binder solution were carried out using the same method described for BI-1. The polymer mixture gave about $26.6 \%$ (w/w) polymer content.

Poly(styrene-co-hydroxybutyl methacrylate-co-methacrylic acid) Binder Solution (BI-3): Methacrylic acid $(7.07 \mathrm{~g}, 0.082 \mathrm{~mol})$, styrene $(14.25 \mathrm{~g}, 0.136 \mathrm{~mol})$ and hydroxybutyl methacrylate $(8.66 \mathrm{~g}, 0.055 \mathrm{~mol})$ were stirred into $69.1 \mathrm{~g}$ PGMEA. Polymerization and preparation of the binder solution were carried out using the method described for BI-1. The polymer mixture gave about $27.2 \%(\mathrm{w} / \mathrm{w})$ polymer content.

Preparation of CFPRs. $40.0 \mathrm{~g}$ of the above pigment paste in appropriate amounts $3 \mathrm{~g}$ of each binder solution, $5.0 \mathrm{~g}$ dipentaerythritol penta-/hexa-acrylate, $1.0 \mathrm{~g}$ Irgacure369 and $0.1 \mathrm{~g}$ FC-4432 were mixed, and PGMEA solvent added to make up $100 \mathrm{~g}$ total weight. The mixture was stirred for 1 hour in a dark room. The resulting solution was filtered using a membrane PTFE (porosity $1.0 \mu \mathrm{m}$ ) filter and exposure to light was avoided.

Preparation of Test Glass Sheets. A small glass sheet $(5 \times 5 \mathrm{~cm})$ was coated with the CFPRs by a spin coater at adequate rpm to achieve target color value, $\mathrm{x}=0.13, \mathrm{y}=$ 0.10 in CIE xy coordination. The coated glass was pre-baked to evaporate the solvent at $80{ }^{\circ} \mathrm{C}$ for 90 seconds. UV exposure was carried out with a patterned photomask of $200 \mathrm{~mJ} / \mathrm{cm}^{2}$ strength at $360 \mathrm{~nm}$. The development process for generating pixels was carried out by spraying an alkalideveloper $(0.5 \%$ potassium carbonate aqueous solution with $0.01 \%$ Surfynol 465 surfactant), followed by a post-bake process for 15 minutes at $220^{\circ} \mathrm{C}$.

Acknowledgments. This study was supported by a grant from the Fundamental R \& D Program for Core Material Technology funded by the Ministry of Knowledge Economy, Republic of Korea.

\section{References}

1. Kubo, M.; Fujioka, S.; Ochi, T.; Narutaki, Y.; Shinomiya, T.; Ishii, Y.; Funada, F. Technical Digest of IDW' '99; SID: Okata, 1999; p 183.

2. Ichimura, K. Advanced Technologies for LCD Color Filters; CMC Publishing: Tokyo, 2006; p 8.

3. Takahashi, T. J. Imag. Soc. Japan 2002, 41, 68.

4. Sugiura, T. J. Print. Sci. Tech. Japan 1996, 356.

5. Jung, I. B.; Ahn, S. H.; Nam, S. Y. Clean Tech. 2008, 14, 21.

6. Baba, K.; Mori, T.; Nakatsuka, K. USP 6,653,031, 2003.

7. Tajima, Y.; Bessho, N.; Takinishi, F.; Yokoyama, Y.; Masuko, H. USP 5,368,976, 1994.

8. Sano, K.; Endo, M.; Shimada, A.; Yokoyama, Y.; Bessho, N. USP $5,530,036,1996$.

9. Yoon, C.; Choi, J. H. Bull. Korean Chem. Soc. 2009, 30(8), 1821.

10. Ichimura, K. Advanced Technologies for LCD Color Filters; CMC Publishing: Tokyo, 2006; 79. 